Home | Archives | About | Login | Submissions | Notify | Contact | Search

ES HOME > VOL. 5, NO. 1 > ART. 2

Copyright (C) 2001 by The Resilience Alliance

The following is the established format for referencing this article:

Roubik, D. W. 2001. Ups and downs in pollinator populations: When is there a decline? Conservation Ecology 5(1): 2. [online] URL: http://www.consecol.org/vol5/iss1/art2/

A version of this article in which text, figures, tables, and appendices are separate files may be found by following this link.

Synthesis, part of Special Feature on Pollinator Decline

\title{
Ups and Downs in Pollinator Populations: When is there a Decline?
}

David Ward Roubik

\section{Smithsonian Tropical Research Institute}

- Abstract

- Introduction

- Methods

O Biological background

○ Variability measures

O Trends and perturbations

$\circ$ Euglossine census techniques and evaluation

- Results

O Community comparisons

○ Long-term trends

- Simultaneous sampling and evaluation of census techniques

- Discussion

O Bee communities over time

ENSO and the bees

Euglossine sampling techniques and long-term sampling strategies

- Responses to this Article

- Acknowledgments

- Literature Cited

- Appendix 1

- $\overline{\text { Appendix } 2}$

- Appendix 3

- Appendix 4

\section{ABSTRACT}

Plant-pollinator systems inherently possess wide variation that limits the applicability of surveys on population dynamics or diversity. Stable habitats are scarcely studied, whereas dynamics in unprotected habitats are less predictable or more compromised by exotic organisms (Apis, in the case of bee surveys). An extensively replicated, long-term study of orchid-bees (Euglossini) was made in protected tropical moist forest in Panama. Over 47,000 bees were recorded in 124 monthly censuses employing 1952 counts. No aggregate trend in abundance occurred (from 1979 to 2000), although four individual species declined, nine increased, 23 showed no change, and species richness was stable. No rare or parasitic species showed decreasing trends, while the most common of the set of bee species studied gradually declined. Biodiversity therefore increased. Recorded variability included $300 \%$ (fourfold) differences in bee abundance among years, and changes in species abundance up to 14-fold. Surveys in dry and wet seasons ( $N=17$ and 18 years, 29 and 31 species, respectively) indicated no numerical changes in the bee assemblage over 21 years. El-Niño climatic events led to brief increases in bee abundance. This detailed survey is deconstructed to assess sampling rigor and strategies, particularly considering the recorded local differences within a single forest.

Year-to-year shifts in bee abundance for three tropical and five temperate bee censuses were comparable. In short studies (2-4 years) and during longer studies (17-21 years), 59 species that included solitary, social, and highly social bees had mean abundances that varied by factors of 2.06 for temperate bees and 2.16 for tropical bees. "Normal" bee populations commonly halved or doubled in 1-yr intervals. Longer term data are only available for the tropics. Stochastic variation and limitations of monitoring methods suggest that minimum series of four years (i.e., three intervals) of several counts during the active season may demonstrate genuine trends. Longer term, 
continuous studies are still needed for meaningful insights on pollinator population shifts in nature.

KEY WORDS: ENSO, Euglossini, abundance variability, bees, census techniques, diversity, pollinators, trends, tropical- temperate comparisons.

Published: April 5, 2001

\section{INTRODUCTION}

Given the task of evaluating divergence in an inherently dynamic system (see, e.g., Wolda 1992, Niemi et al. 1998), no valid assessment is possible unless there is a firm grasp of variability. Brief inspection of multiple-year bee population dynamics illustrated by Figs. 1-3 demonstrate that continuous or frequent sampling is necessary in a census, both to document seasonal trends and to measure year-to-year change. A random data point taken from the annual population curve shown in Fig. 2 is inadequate for discussing local population levels or for comparing multiple years. The same reasoning applies to more restricted spatial or temporal scales. Once variation in space and time are taken into account, do collected data reveal the larger trends and true population status? If samples are taken repeatedly, then analysis of perturbation requires the removal of dependence in such a data series to allow a test for departure from past trends. Time-series intervention analysis, currently among the more sophisticated tools to deal with this problem (Roubik 1983, Hilborn and Mangel 1997), requires 30 or 40 data points for a baseline. Many studies, however, are restricted to short sampling periods and few years. Alternative data analyses are performed (e.g., Cane and Payne 1993, Basset et al. 1998), but many questions remain concerning trends, variability, species richness, and biodiversity. In contrast, long-term surveys allow resolution of major issues with relatively simple tests. For example, they can show whether there has been a perturbation or whether surveys done on a considerably smaller scale document significantly more than species presence (or absence) in a biased sample. Once large numbers of data points are available, the degree of variation attributable to so-called "noise": (field conditions, sampling techniques, cyclic climatic events) vs. bona fide trends may become reasonably clear. This paper describes the findings of long-term studies on tropical bees in protected forest area in central Panama, and attempts to rigorously evaluate both techniques and results.

Fig. 1. Euglossine bees recorded on 124 standardized monthly censuses at km 8.0 on Pipeline Road, in Parque Nacional 


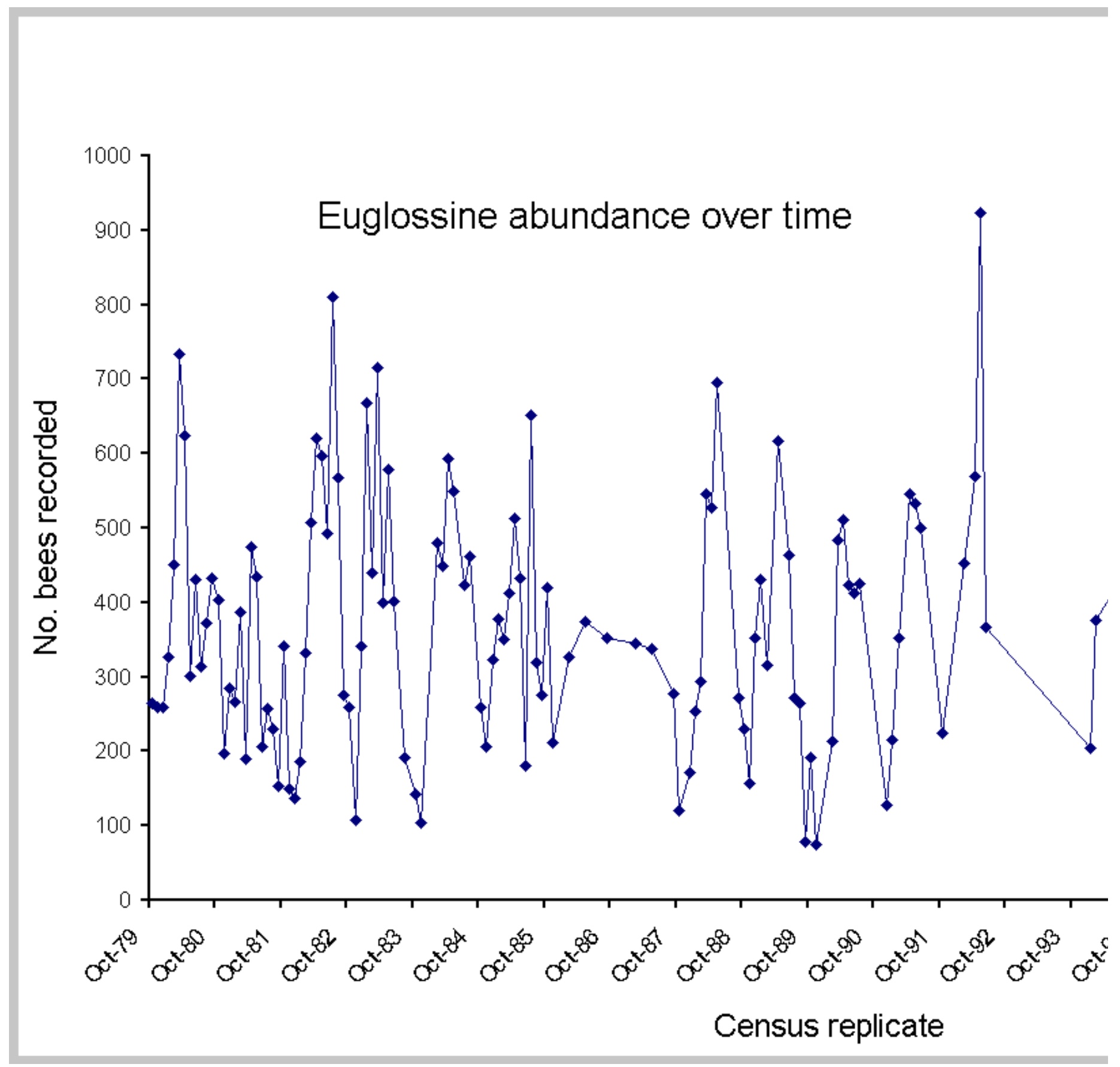

Fig. 2. Monthly mean abundance, standard deviation, and comparisons of ENSO and wet years to pooled means for eug Soberania, Panama. 


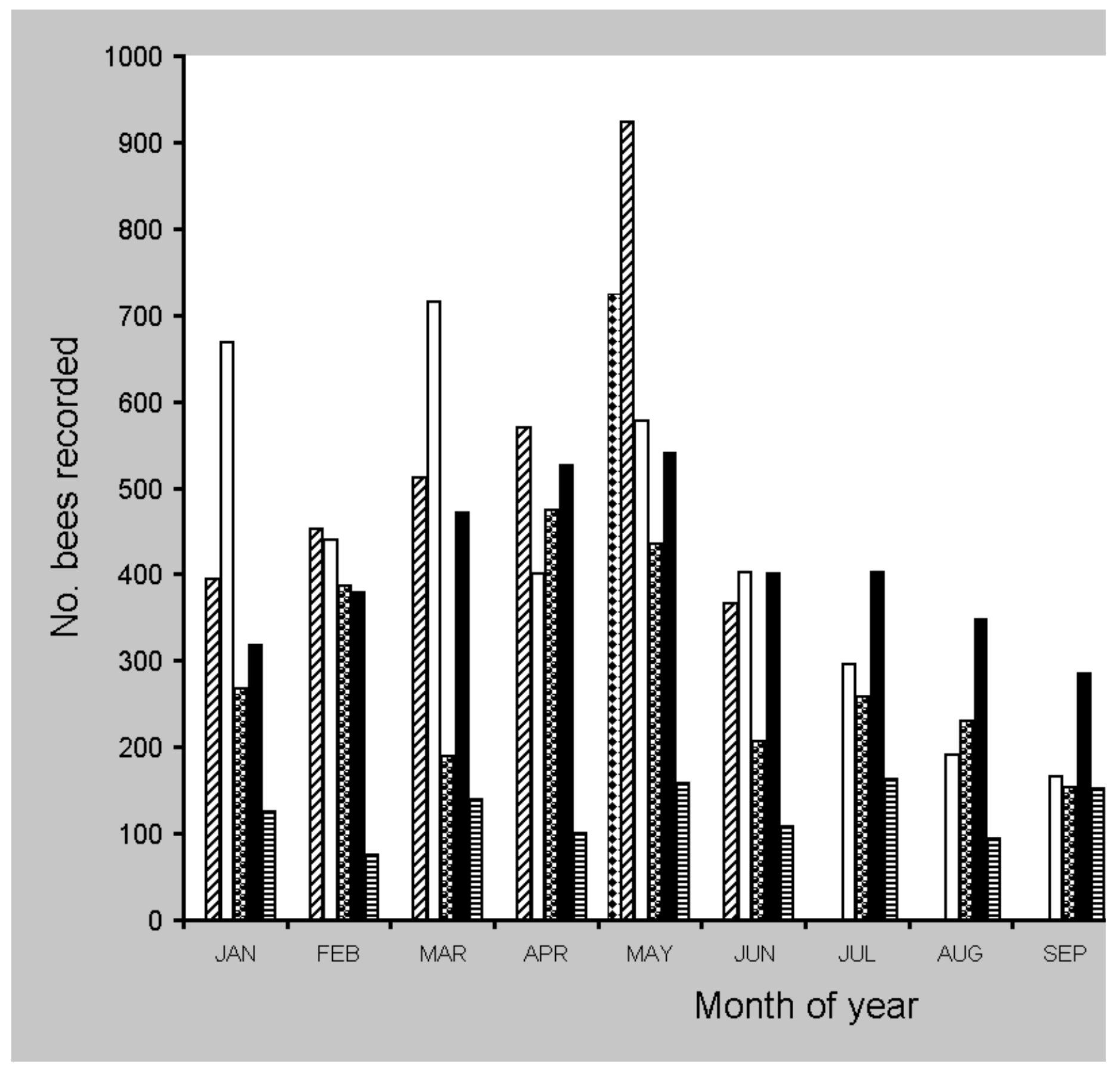

Fig. 3. Time trends in a euglossine bee assemblage over 21 years for replicated censuses during mid dry season (Febru Nacional Soberania, Panama. Interpolated missing data were plotted for February (1993, 1995-1997) and May (1993-1 


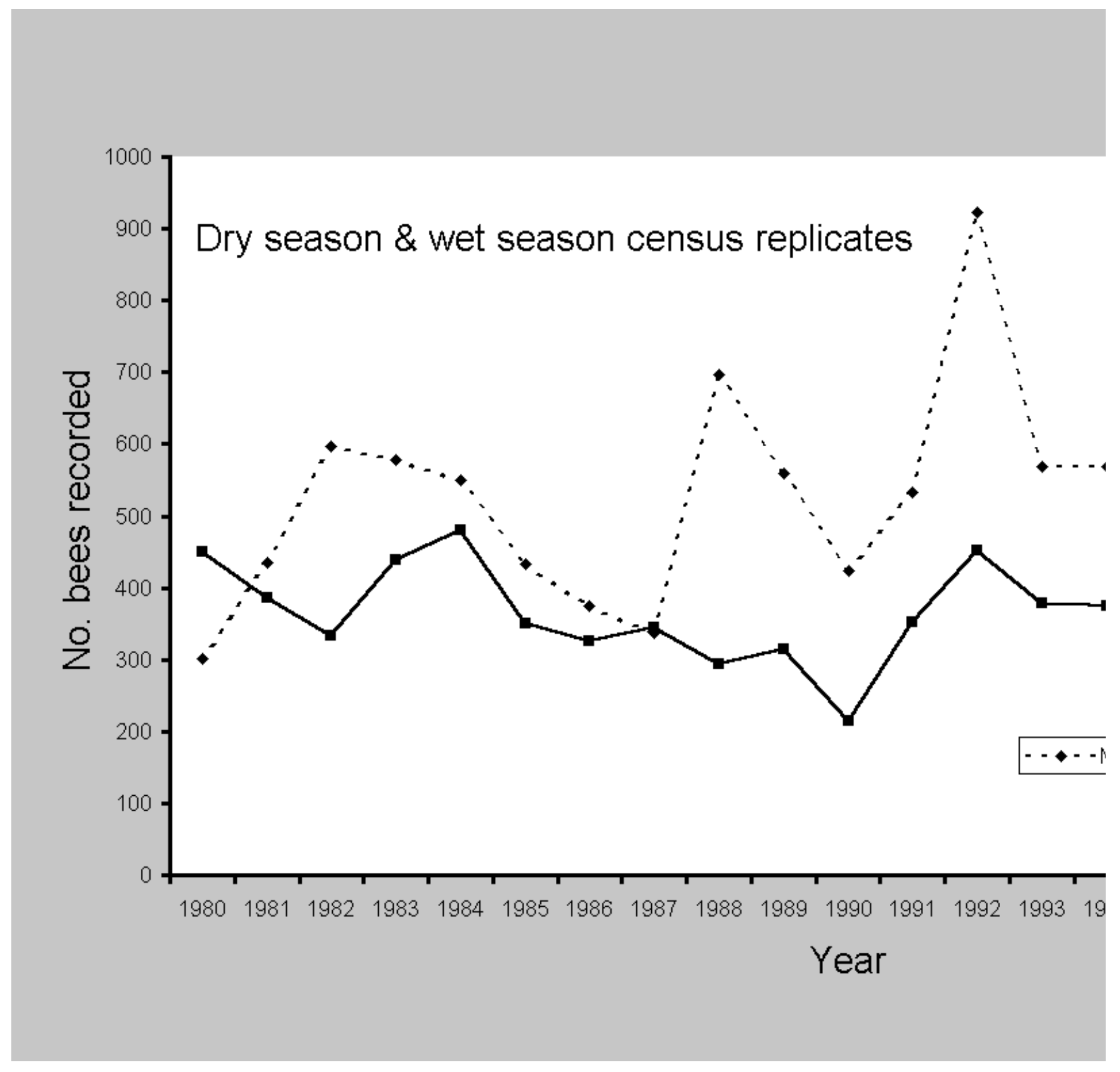

Few systematic studies exist of relative or absolute pollinator abundance (e.g., Ginsberg 1983, Roubik 1989, 1996a,b, 2000, Banazak 1995, Buchmann and Nabhan 1996, Matheson et al. 1996, Frankie et al. 1998, Roubik and Wolda 2000). In general, long-term data are not quantitative; quantitative data include too few years or are collected in heavily disturbed habitats; or sampling is too sporadic to clearly trace trends or carefully consider species richness or the allied question of biological diversity. Moreover, animals such as pollinators with large foraging areas or home ranges present special problems for surveys. A noteworthy exception exists for bees. Male euglossine bees are attracted to chemical compounds (Dressler 1982, Janzen et al. 1982, Ackerman 1983, Powell and Powell 1987, Roubik 1993, Eltz et al. 1999, Peruquetti et al. 1999). This behavior offers the possibility for replicable surveys of pollinators, without extensive destructive sampling or elaborate methodology (see also Pearson and Dressler 1985, Roubik and Ackerman 1987, Roubik 1989, 1992, Becker et al. 1991, Oliveira and Campos 1995).

Population studies of bees allow graphic understanding of trends or possible decline in pollinator abundance, and perhaps more fundamental, what kinds of abundance variability can be expected. I sampled euglossine bees consistently for 22 years, over three strong El-Niño events accompanied by seasonal drought and one exceptionally rainy dry-season. I repeated the studies of Armbruster (1993), who made simultaneous euglossine surveys $1 \mathrm{~km}$ apart in a Panamanian forest, and obtained differing numerical results. My data demonstrate that large fluctuations sometimes occurred in relatively undisturbed habitat, driven primarily by ENSO events, and that long-term studies substantially clarified results taken on a small temporal scale. Spatial scale was less important. Short- and long-term bee census studies from California, Peru, and Panama were examined to gain a more general picture of variability in bee abundance within nature preserves. Basic recommendations are offered. 


\section{METHODS}

\section{Biological background}

Euglossine bees, (Euglossini, family Apidae) are only found in the neotropics and have approximately 200 species, 70 of which live in Panama (Dressler 1982, Roubik 1989). Four of the five genera occur there, including the euglossine clepto-parasite Exaerete. Almost all bees except Eufriesea are active all year, and all local species except Eufriesea purpurata and Euglossa cyanura come to three chemical baits used to attract males. Males land on the baits and are fooled into collecting these chemicals as products equivalent to those at flowering orchids, aroids, or on fungi (see Fig. 4; Roubik and Ackerman 1987 ; D. Roubik, personal observation). Large euglossines make long flights of many kilometers (Janzen et al. 1982), and fly in canopy or open sun conditions to a far greater extent than most members of the genus Euglossa, which comprise most local species (Roubik 1993). Euglossines generally have colonies of two to a few dozen related individuals that may re-use the parental nest. Finally, and most important for field surveys of euglossine communities, mimicry between species, even across genera, is common (see Becker et al. 1991). A field key and reference collection greatly facilitated studies presented here, in which no exhaustive collections or voucher specimens were needed for the thousands of bee counts. For details, see Roubik and Ackerman (1987) and Appendix1).

Fig. 4. Eufriesea arriving on a bait pad at Cerro Campana, Panama.

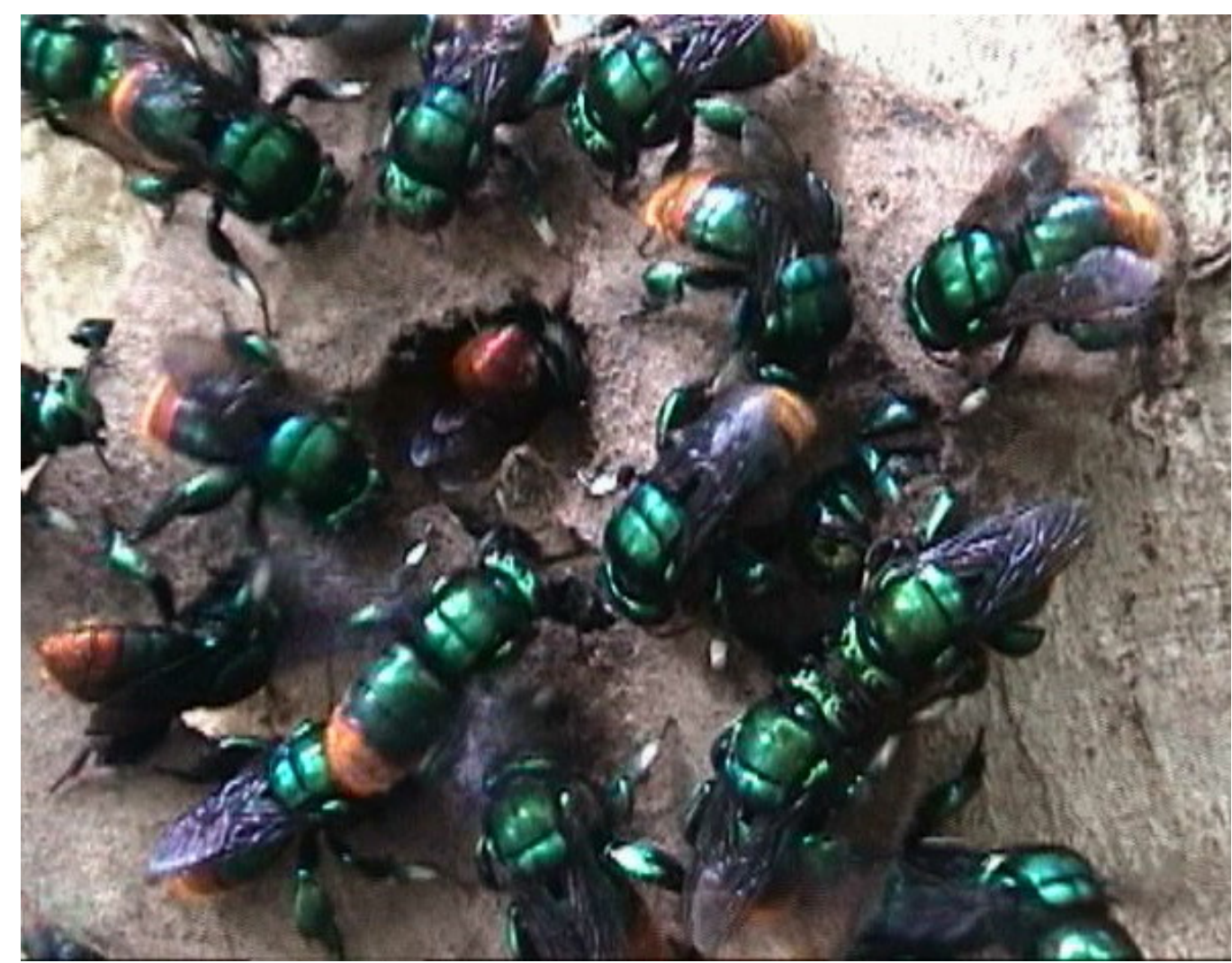

\section{Variability measures}

Bee population variability was determined for protected habitats. I evaluated sequential yearly bee abundance recorded in California (Frankie et al. 1998); Tambopata National Park, Peru (Pearson and Dressler 1985); Barro Colorado Island (BCI), Panama (Wolda and Roubik 1986, Roubik and Wolda 2000); Curundu, Parque Metropolitano, Panama (Roubik 1989: 334; and unpublished data); and the present Euglossini surveys from Parque Soberania along Pipeline Road, Panama. Five different census techniques were used, respectively: (1) counts of all individual immature bees within bee nesting blocks supplied with nesting holes ad libidum; (2) counts of males caught at chemical baits; (3) counts of females caught in two aerial funnel traps with continuously operated ultraviolet fluorescent lights; (4) counts of both male and female bees resting at night in a nesting block that contained nesting holes ad libidum; and (5) counts of male bees collecting chemical attractants during 16 repeated censuses on three chemical baits. The Tambopata site was by far the largest forest area, the Panama sites were smaller forests, both primary and secondary, extending more than several kilometers in all directions. Both the Panamanian and the Peruvian study areas are lowland sites. Barro Colorado Island is $16 \mathrm{~km}^{2}$, presumably experiencing modest isolation from surrounding mainland forests, less than $1 \mathrm{~km}$ distant. The California sites were small nature preserves or parks, similar in size to BCI Nature Monument, near locally mixed secondary growth or agricultural land, from sea level to approximately $1000 \mathrm{~m}$ elevation. 
and Pipeline Road); short-term but during contrasting parts of the active season (wet and dry periods in Tambopata, Peru and Curundu, Panama); and, as a comparable strategy, taken primarily during the summer (California). The abundance data from Curundu on Centris analis considered the first 26 weeks of 1981-1984, which spans dry and early wet seasons, after which nesting activity greatly declines. Abundance data on Euglossini of Parque Soberania were evaluated for the peak month (May) and the middle of the dry season (February) for each sequential census from 1980 to 2000.

Absolute abundance change was scored to produce an index of variability, in contrast to measures of statistical variance (Wolda $1979,1992)$. Variability is a straightforward metric that describes abundance changes in a species or set of species. Short-term data sets of a few years' duration cannot demonstrate trends (see Discussion), but they do show the magnitude of change. Ratios of adjacent bee counts for censuses were computed by placing the larger of the two counts in the numerator. As such, all values were real numbers, greater than one. Variability for a bee assemblage was then computed as a mean of the "order of magnitude" change between sequential censuses. For example, if one species declines by $90 \%$ and then doubles from one census to the next, its absolute abundance change, simplified from raw census counts, is $[(10 / 1)+(2 / 1)] / 2=6.0$. The mean of this metric was the index of variability for species at a census site. Numbers from adjacent counts were used; thus, each data point was compared to that before and after it, producing $n-1$ measurements for $n$ points, for each species. Because some sampling periods contained no counts of individual species (Euglossini on Pipeline Road in February and May), a numerical method of adding one individual to all species counts was employed. This avoided placing a count of zero in the denominator of ratios.

\section{Trends and perturbations}

No single measure seemed robust enough to consider all aspects of decline or change; thus, five different tests were made. Statistical change in euglossine assemblages was approached with regression analysis and paired $t$ tests, using SYSTAT 7.0 for Windows (SPSS 1997). Linear regression evaluated: (1) aggregate totals and individual species abundance on all census dates from the first count in October 1979 to the last in May 2000 (Fig. 2); (2) total counts of all species in May and February; and (3) arrival times for individual species on each census during 1981-2000. The two months were selected because they provided the longest available series of replicated months and were from both wet and dry seasons. More important, May was consistently the month of maximum abundance and species (Fig. 3; see Roubik and Ackerman 1987). The complete data set consisted of many gaps in months, particularly during 1987-1988 and after 1994, and thus was not balanced across years. Counts after 1994 were concentrated in months showing higher abundance. However, detection of a long-term trend should be possible using this data series. Because later counts were biased toward higher abundance, the series provides a conservative test of potential decline. The dry-season and wet-season focal months (February and May) are not, of course, the same as entire years, and, as shown in Fig. 3, were not always in concordance. However, they provide the most consistent data series available for 21 years, with three or four interpolated data points added to compensate for lack of census data in 1993-1997 (Fig. 4). As a final test that included all of the variation recorded over time, and that did not rely on substitution of missing data, contemporary abundance in February and May of 2000 was compared to the means of all preceding censuses using paired $t$ tests. This is the simplest form of a repeated-measures design: two measurements were made on abundances within a group of bee species. For these analyses, individual species were included only if their mean annual abundance exceeded 0.1 in the period 1980-1999. Several species were relatively rare (Appendix 1), but a few species were all but absent, and thus could not be used to evaluate numerical changes in the bee community. Clearly, no species were "gained" or "lost" during the study (see Results).

The environmental factors most implicated as possible causes of bee abundance changes were frequent rain throughout the dry season of 1981 (Wolda and Roubik 1986, Roubik and Wolda 2000) and strong El- Niño Southern Oscillation (ENSO) events, which created unusually long dry seasons in 1982-1983, 1992, and 1997 (see Wright et al. 1999). The ENSO event of 1983 was distinctive in having an earlier start, during November of 1982. An extremely wet year occurred in 1981. Using the paired ttest, these years were compared to the other, non-ENSO years in bee abundance, both during May and February.

\section{Euglossine census technniques and evaluation}

Euglossine censuses in Panama were taken by presenting three chemical baits for $4 \mathrm{~h}$, while counting all species and individuals every 15 min and recording the timing of their first arrival throughout the period (Roubik and Ackerman 1987). Chemical baits consisted of reagent-grade methyl salicylate, cineole, and skatole, applied in standard amounts to herbarium blotter pads of 7 $\mathrm{cm}$, tacked to tree trunks in the shade, $1.5 \mathrm{~m}$ above the ground. The same trees were used in all studies. Live bees were identified in the field using a key to local species, prepared by R. L. Dressler in 1969 and revised in 1981 . The data under consideration are from only one of three sites used in long-term studies (see Roubik 1992, 1996a).

Two general methods, one statistical and the other a planned field study, were used to examine whether the euglossine baiting results accurately reflected abundance in the habitat. First, data on the arrival times for the first individual of each species at the Pipeline Road site were analyzed ( $N=98$ censuses taken from 1981 to 2000). A histogram of arrival times (Fig. 5 ) suggested that the census period of $4 \mathrm{~h}$ was necessary to detect all species, and that bees were moving into the range at which baits were effective. Regression analysis, an $F$ test for a slope significantly different from zero, was performed on bee abundance plotted against time of first arrival. The null hypothesis was that more common bees were no more likely to arrive earlier at the attractants. In other words, the attractants may largely bring in those species that happen to be closest to the position of baits, but do not reflect the population status in a broader area: the local habitat. A corollary is that the volatile compounds do not attract bees from a large area, or that the bees themselves are relatively sedentary or patchy in distribution. The mean timing of first arrival of each species to baits was plotted against the total number of bees recorded on a census date. To check this general test, abundant species of five size classes were examined individually. Second, the spatial replicability of census results was studied through simultaneous sampling, near Armbruster's (1993) site. This included the same spot where I take the monthly euglossine census. For parallel replicated studies, three more sites were added, each separated from its neighbor by $0.5 \mathrm{~km}$. The sites were on $\mathrm{km} 8.0-9.5$ of Pipeline Road. Study dates were 18 November, 18 December, and 18 January (1997-1998). The parallel sites were visited every 20 min by driving between them. My standard methods were employed (three different chemical baits; 16 censuses beginning at 0830 ). 
Fig. 5. Timing of first arrival at baits for individual species of euglossine bees during 98 4-hr census studies at Parque Soberania, Panama.

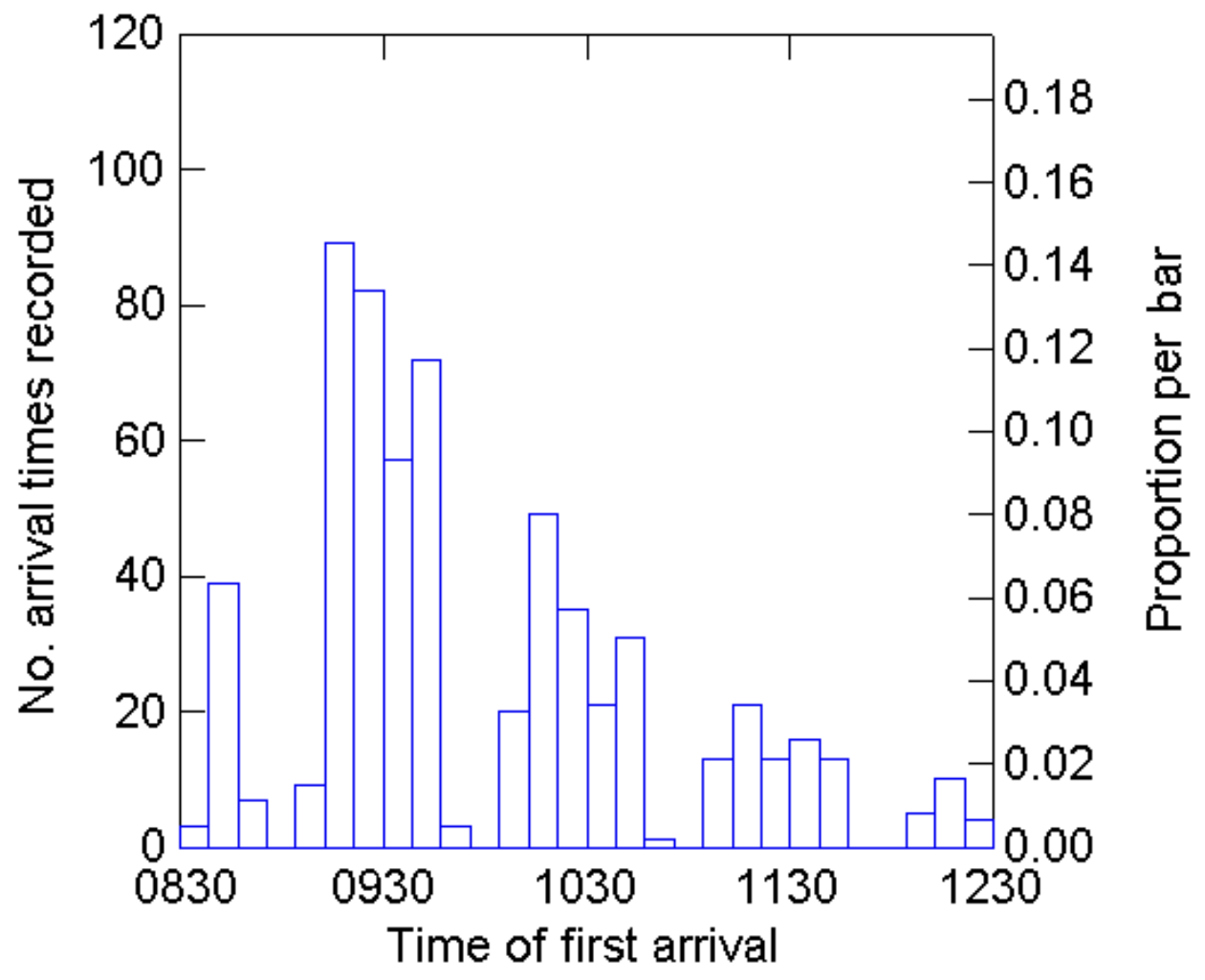

A qualitative consensus analysis was made of trends and abundance data in the simultaneous censuses. I asked the following questions: Are the same species found at all sites and in similar abundance ranks? Do the tendencies to increase or decrease in number across time agree for each species at each site, and do their peak numbers coincide? Are there notable differences among sites relative to bee abundance and diversity?

A trend was defined as increase or decrease recorded in adjacent months. Species trends during the 2-mo census interval were scored on a per site basis using the raw data in Appendix 3. Trends were compared among the sites, so that if all displayed the same trend for a species, eight trends (100\%) were consistent during the study. Similarity between sites was also scored by abundance ranks and timing of peak abundance. The 10 most abundant species were compared between sites, and the top 13 ranks were taken into consideration for coincidence in peak number for the species that were present at all sites.

\section{RESULTS}

\section{Community comparisons}

Temperate and tropical habitats presented essentially the same picture of change in bee populations. Variability was scored for a total of 59 bee species (Table 1). Bees were either solitary (Rhinetula, Ptiloglossa, Megachile, Osmia, Centris, some Euglossini), social (Megalopta, some Euglossini), or highly social (Meliponini, Apis). The order of magnitude in change between years ranged from 1.36 (Euglossini in Parque Soberania) to 5.04 (honey bees on BCI). The different tropical habitats displayed closely similar variability in Euglossini, whether measured over 2 or 20 years. However, two species of Centris studied in Panama showed markedly different variability, with order changes of 1.77 and 4.74 in two different habitats, and with data gathered during 4 and 17 years. The species studied for the longest time showed the greatest absolute fluctuation. Such a general relationship also was evident when the lowest and highest numbers of each species were compared over a relatively long period. For example, the raw abundance of each euglossine species varied from about three- to 14-fold (Appendix 2) over $21 \mathrm{yr}$. Likewise, the mean abundance of Meliponini varied nearly 40-fold when extreme years on BCI were compared. On average, temperate bee species varied by a factor of 2.16 between years. Tropical species varied by a factor of 2.06 ( $g r a n d$ 
mean). Honey bees in the wild, an invading species new to the Americas, were not included in this result. The African honey bees on BCI were the most variable in abundance of all bees studied.

Table 1. Annual variability in bee abundance (see Methods), from short- and long-term censuses in two tropical (Peru and Panama) and one temperate (California) regions. Bee families identified below are Apidae (AP), Megachilidae (MG), Halictidae (HAL), and Colletidae (COL).

\begin{tabular}{|l|c|c|c|c|}
\hline \multicolumn{1}{|c|}{ Bees } & No. species & $\begin{array}{c}\text { Annual } \\
\text { variability }\end{array}$ & No. years & Source \\
\hline Euglossini (AP) & 6 & 1.77 & 2 & $\begin{array}{c}\text { Pearson and } \\
\text { Dressler (1985) }\end{array}$ \\
\hline Osmia (MG) & 1 & 2.46 & $2-3$ & $\begin{array}{c}\text { Frankie et al. } \\
\text { (1998) }\end{array}$ \\
\hline Megachile (MG) & 3 & 2.07 & 3 & $\begin{array}{c}\text { Frankie et al. } \\
\text { (1998) }\end{array}$ \\
\hline Centris (AP) & 1 & 1.77 & 4 & $\begin{array}{c}\text { Roubik (1989) and } \\
\text { unpublished data }\end{array}$ \\
\hline Apis (AP) & 1 & 5.04 & 10 & $\begin{array}{c}\text { Roubik and Wolda } \\
\text { (2000) }\end{array}$ \\
\hline Megalopta (HAL) & 2 & 2.15 & 17 & $\begin{array}{c}\text { Roubik and Wolda } \\
\text { (2000) }\end{array}$ \\
\hline Rhinetula (HAL) & 1 & 3.45 & 17 & $\begin{array}{c}\text { Roubik and Wolda } \\
\text { (2000) }\end{array}$ \\
\hline Centris (AP) & 1 & 4.74 & 17 & $\begin{array}{c}\text { Roubik and Wolda } \\
\text { (2000) }\end{array}$ \\
\hline Meliponini (AP) & 10 & 4.06 & 17 & $\begin{array}{c}\text { Roubik and Wolda } \\
\text { (2000) }\end{array}$ \\
\hline Ptiloglossa (COL) & 1 & 2.45 & 17 & $\begin{array}{c}\text { Roubik and Wolda } \\
\text { (2000) }\end{array}$ \\
\hline Euglossini (AP) & 32 & 1.36 & 20 & Roubik, this study \\
\hline
\end{tabular}

*Mean absolute change (ratio of higher to lower value) of sequential census counts.

The value of the raw variability index is compromised by a skew toward lower values (Fig. 6), here plotted only for the bees with relatively long data sets: the 48 species studied in Panama. Each count in the graph represents the mean variability ratio or index for one species. A natural-logarithm transformation (Fig. 6) made the sample indices normal in distribution, and although both graphs presented one outlier of high variability, neither was bimodal. Statistical comparisons of change in bee populations might be made using such log-transformed annual abundance data.

Fig. 6. Frequency distributions of year-to-year variability in total counts for Panamanian bees. Raw data variability and their In transformation are shown for 18 yearly replicates of 33 Euglossini from Pipeline Road, Parque Soberania, and for 15 native species (17 yearly replicates) for Barro Colorado Island, Panama. 


\section{a)}
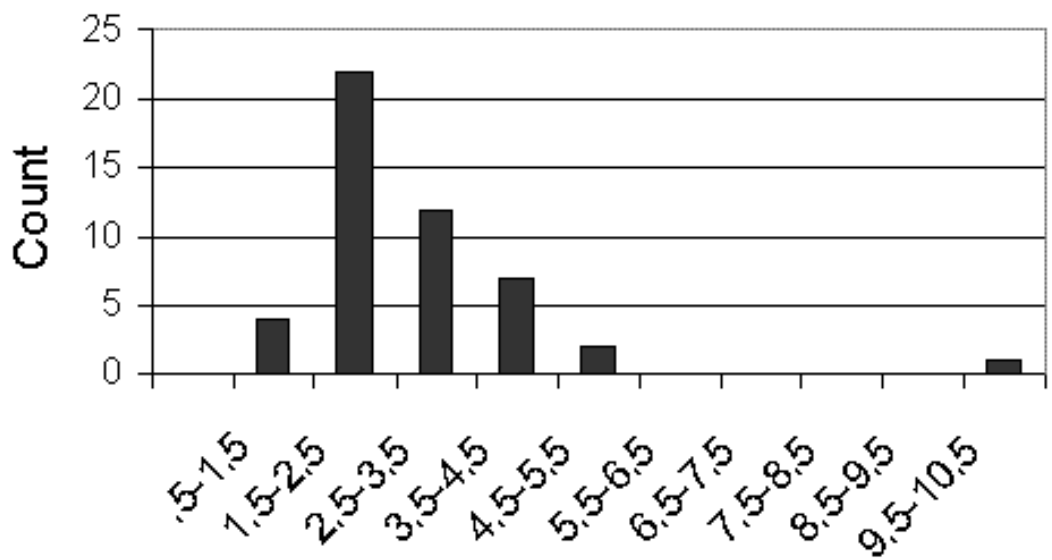

\section{Variability Index}

b)
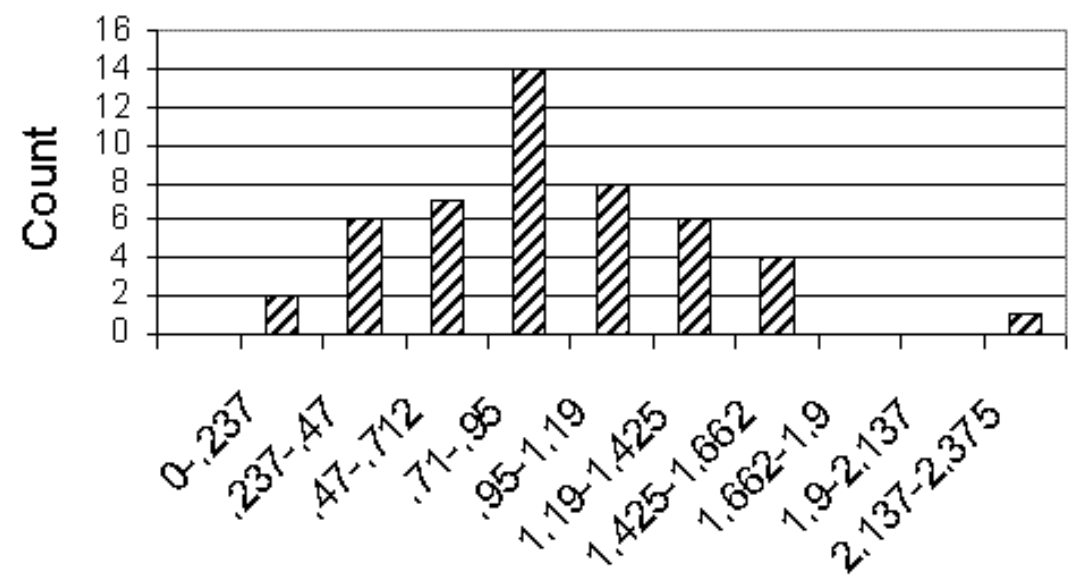

$\ln ($ Variability Index)

\section{Long-term trends}

No significant regression was found for aggregate bee abundance over $22 \mathrm{yr}(F=1.96 ; P=0.16 ; \mathrm{df}=1,123)$. The data include 46,921 individual bees counted at the baiting stations (Appendix 1). Individual species varied, but only four species declined (Euglossa imperialis, E. dressleri, E. gorgonensis and E. dodsoni), whereas 23 species remained unchanged and nine species increased. If the final two censuses are excluded, for 2000 (when anomalously high numbers of one species occurred), the aggregate and individual trends are no different. Of further interest, neither of the parasitic species Exaerete smaragdina and Exaerete frontalis changed, nor did the rare species (see Appendix 1 ). The paired $t$ tests of abundance showed no significant change in May or February $(t=-1.26, P=0.21, \mathrm{df}=30 ; t=1.13, P=0.27, \mathrm{df}=28$, respectively). Results indicate that abundance of each species in 2000 was indistinguishable from past years for the dry-season and wet-season months of February and May 1980-1999 (Table 2). Further assessment of abundance for the two comparisons (Table 3) shows that in May 2000, 15 species increased and 15 decreased, relative to the past mean. In February, eight species increased and 21 decreased. As shown in Fig. 4, although no trend was found for February, there was an increase in aggregate bee abundance recorded in May $(F=0.03, P=0.86, \mathrm{df}=1,19 ;$ and $F=10.21, P=0.004, \mathrm{df}=1,19$, respectively). The statistical increase was due to the 332 Euglossa dissimula recorded in 2000, almost four times the mean (Appendix 2). Without this species, May showed no increase.

Table 2. Comparison of yearly euglossine bee census counts (paired ttest) to establish whether change occurred over a 20-yr interval (1980-1999 or 2000). Abundances in May and February for 33 species were compared, using the mean for 16 or 17 census years and the monthly census for 
1999 or 2000. "Trend" is the tally of species displaying each of the three trends assessed by regression analysis over the indicated intervals.

\begin{tabular}{|c|c|c|c|c|c|c|c|c|c|}
\hline & & & & & & & & Trend & \\
\hline Month & Period & $\begin{array}{c}\text { No. } \\
\text { years }\end{array}$ & $\begin{array}{c}\text { Mean } \\
\text { abundance } \\
\text { per } \\
\text { species }\end{array}$ & df & $t$ & $\boldsymbol{P}$ & Up & Down & None \\
\hline May & 1999 & 1 & 21.42 & 32 & 1.47 & 0.15 & 16 & 8 & 9 \\
\hline May & $1980-1999$ & 17 & 16.56 & & & & & & \\
\hline February & 2000 & 1 & 8.87 & 32 & -1.35 & 0.19 & 4 & 15 & 14 \\
\hline February & $1980-2000$ & 18 & 11.54 & & & & & & \\
\hline
\end{tabular}

Table 3. Seasonal census results for euglossine bees at the Pipeline Road site, Parque Nacional Soberania, Panama, 1980-2000.

\begin{tabular}{|c|c|c|c|c|c|}
\hline $\begin{array}{c}\text { February } \\
\text { mean, } \\
\text { 1980-1999 }\end{array}$ & \begin{tabular}{|c|} 
February \\
2000
\end{tabular} & $\begin{array}{c}\text { February bee } \\
\text { species }\end{array}$ & $\begin{array}{l}\text { May bee } \\
\text { species }\end{array}$ & \begin{tabular}{|l|} 
May mean, \\
$1980-1999$
\end{tabular} & $\begin{array}{l}\text { May } \\
2000\end{array}$ \\
\hline 86.69 & 43 & Eug. imperialis & Eug. imperialis & 146.88 & 145 \\
\hline 82.19 & 65 & Eug. tridentata & Eug. tridentata & 46 & 39 \\
\hline 4 & 2 & Eug. dressleri & Eug. dressleri & 4.64 & 2 \\
\hline 48.19 & 46 & Eug. despecta & Eug. despecta & 81.47 & 111 \\
\hline 0.27 & 0 & Eug. cybelia & Eug. cybelia & 0.46 & 2 \\
\hline 32.38 & 61 & Eug. dissimula & Eug. dissimula & 94.65 & 332 \\
\hline 1.87 & 1 & $\begin{array}{c}\text { Eug. } \\
\text { gorgonensis }\end{array}$ & $\begin{array}{c}\text { Eug. } \\
\text { gorgonensis }\end{array}$ & 1.85 & 3 \\
\hline 1.75 & 2 & Eug. dodsoni & Eug. dodsoni & 2.46 & 0 \\
\hline 6.44 & 13 & Eug. bursigera & Eug. bursigera & 17.06 & 37 \\
\hline 0.93 & 0 & Eug. championi & Eug. championi & 2.83 & 6 \\
\hline 1.67 & 0 & Eug. deceptrix & Eug. deceptrix & 2 & 0 \\
\hline 4.93 & 6 & $\begin{array}{c}\text { Eug. } \\
\text { crassipunctata }\end{array}$ & $\begin{array}{c}\text { Eug. } \\
\text { Crassipunctata }\end{array}$ & 9.12 & 23 \\
\hline 2.06 & 2 & Eug. hansoni & Eug. hansoni & 4.16 & 3 \\
\hline 8 & 1 & Eug. sapphirina & Eug. sapphirina & 11.91 & 8 \\
\hline 2.88 & 2 & azureoviridis & azureoviridis & 3.68 & 0 \\
\hline 1.4 & 2 & Eug. igniventris & Eug. igniventris & 0.27 & 1 \\
\hline 0.14 & 0 & Eug. hemichlora & Eug. mixta & 16.15 & 15 \\
\hline 9.13 & 6 & Eug. mixta & $\begin{array}{c}\text { Eug. } \\
\text { heterosticta }\end{array}$ & 1.54 & 0 \\
\hline 2.06 & 2 & $\begin{array}{c}\text { Eug. } \\
\text { heterosticta }\end{array}$ & Eug. allosticta & 5 & 6 \\
\hline 6.13 & 7 & Eug. allosticta & Eug. cognata & 18.56 & 24 \\
\hline 7.19 & 4 & Eug. cognata & variabilis & 2.59 & 1 \\
\hline 7.31 & 2 & Eug. variabilis & Exa. frontalis & 7.62 & 11 \\
\hline 1.38 & 1 & Exa. frontalis & $\begin{array}{c}\text { Exa. } \\
\text { smaragdina }\end{array}$ & 0.41 & 0 \\
\hline 0.23 & 0 & $\begin{array}{c}\text { Exa. } \\
\text { smaragdina }\end{array}$ & Eul. cingulata & 25.71 & 26 \\
\hline 28.31 & 6 & Eul. cingulata & Eul. nigrita & 24.47 & 15 \\
\hline 21.19 & 11 & Eul. nigrita & Eul. meriana & 14.03 & 25 \\
\hline 6.5 & 16 & Eul. meriana & $\begin{array}{c}\text { Eul. } \\
\text { bombiformis }\end{array}$ & 2.56 & 15 \\
\hline
\end{tabular}




\begin{tabular}{|c|c|c|c|c|c|c|}
\hline 3.38 & 7 & $\begin{array}{c}\text { Eul. } \\
\text { bombiformis }\end{array}$ & & $\begin{array}{c}\text { Euf. } \\
\text { schmidtiana }\end{array}$ & 1.57 & 2 \\
\hline 3.75 & 2 & Euf. pulchra & & Euf. anisochlora & 1.04 & 0 \\
\hline & & & & Euf. pulchra & 2.03 & 3 \\
\hline
\end{tabular}

Note: Genera are abbreviated as Eug., Euglossa; Euf., Eufriesea; Eul., Eulaema; and Exa., Exaerete.

This euglossine assemblage showed no detectable change in diversity over 22 years, despite abundance shifts shown by the regression tests. Twenty species of euglssines were found in wet season and dry season comparisons for 1980 and 2000 . The species not encountered in May 2000, but recorded in 1980 on this date (see also Table 3), were seen within the previous year, with the exception of Eufriesea anisochlora, which was a transient, seen only in May of 1980, 1983, 1986, and 1991. Similarly, all species missed in February 2000 but seen in 1980 had been recorded in 1999 or 1998. It is instructive to examine two widely separated years that had similar total bee counts. February of 1980 and 1999 provide such a comparison, giving an "abundance-free" estimate of diversity (total abundance and species number are positively correlated in euglossine censuses; see Roubik and Ackerman 1987). In 1980 (450 bees counted) a single individual of one species was seen that was not recorded in 1999. In February 1999 (459 bees counted), four species were seen that were not recorded in February of 1980 . All of these were relatively uncommon species. Among remaining bee species and months or years, inspection of my unpublished field data and Appendix 1 suggests that Euglossa asarophora, Eufriesea anisochlora, Eufriesea Iucifera, Eufriesea duckei, Eufriesea dressleri, Eufriesea concava, Euglossa villosiventris, Eulaema leucopyga, Eulaema speciosa, Euglossa turbinifex, Euglossa oleoleucens, Euglossa ignita, and Euglossa purpurea still occur sporadically in this habitat, but are probably transients (see Janzen et al. 1982). I have seen no Euglossa villosiventris at Pipeline Road since 1990, but 19 of its 21 previous sightings were in November through January, when I have made only three census studies since 1994. It is important to note that the Pipeline Road area, like Barro Colorado Island, is in the middle of the Panamanian isthmus, and wetter or drier forests at similar elevation are within $20 \mathrm{~km}$. It is likely that animals from these adjacent forests are occasionally found in the study area.

Environmental factors implicated as possible causes of bee abundance changes were frequent rain throughout the dry season of 1981 and strong El-Niño Southern Oscillation (ENSO) events, which created unusually long dry seasons in 1982-1983, 1992, and 1997 (see Wright et al. 1999). Changes scored for euglossine bee populations are evident in Fig. 3. Compared to the means for all other years (2000 was not included because of the anomalous superabundance of Euglossa dissimula), bee numbers were generally higher during ENSO years, particularly in May, the month of peak abundance, in 1997, 1992, and 1983. The ENSO event of 1983 was distinctive in having an earlier start, during November of 1982 . Bee abundance peaks in this year shifted back to January and March (Fig. 2). The extremely wet year of 1981 showed a deficit in bee abundance during March (late dry season) and June through September (mid wet season). For the peak abundance in the early wet season, a difference of $300 \%$ was recorded between May1980 and May 1992 (Appendix 2). The dry-season samples (February) showed no significant differences during two ENSO years $(1983,1992)$ or the wet year, 1981 (Table 4). However, the May censuses showed highly significant increases in the ENSO of 1992 (mean per species of 28.96, compared to a mean of 16.09 on other years) and a marginally significant decrease during the rainy year of 1981 . The year of 1997 also yielded relatively high numbers in May (Figs. 2 and 3). A slightly different analysis, in which all years were combined to yield the mean, and in which all species were left in the census, produced nearly identical results. The exception was 1981, which appeared lower, with a mean per species of 12.02 , compared to the grand mean of $15.8(t=1.93, \mathrm{df}=34, P=0.06)$.

Table 4. Bee abundance change scored for strong environmental variation (ENSO and extremely wet years). Comparisons are by by pairs of years ( $t$ test) of species abundance in euglossine bee assemblages.

\begin{tabular}{|c|c|c|c|c|}
\hline \multirow{2}{*}{$\begin{array}{l}\text { Comparison } \\
\text { and season }\end{array}$} & \multirow[b]{2}{*}{\begin{tabular}{|c|} 
Mean \\
abundance \\
per \\
species
\end{tabular}} & \multirow[b]{2}{*}{ df } & \multirow[b]{2}{*}{$t$} & \multirow[b]{2}{*}{$\boldsymbol{P}$} \\
\hline & & & & \\
\hline \multicolumn{5}{|l|}{$\begin{array}{l}\text { Feb. (dry } \\
\text { season) }\end{array}$} \\
\hline Very wet: 1981 & 14.66 & 26 & 0.21 & 0.83 \\
\hline Other years & 14.02 & & & \\
\hline ENSO: 1983 & 15.92 & 26 & 0.52 & 0.61 \\
\hline Other years & 13.93 & & & \\
\hline ENSO: 1992 & 16.66 & 26 & 1.05 & 0.30 \\
\hline Other years & 13.90 & & & \\
\hline
\end{tabular}




\begin{tabular}{|c|c|c|c|c|}
\hline $\begin{array}{l}\text { May (wet } \\
\text { season) }\end{array}$ & & & & \\
\hline Very wet: 1981 & 13.53 & 31 & 1.71 & 0.09 \\
\hline Other years & 17.46 & & & \\
\hline ENSO: 1983 & 18.15 & 31 & 0.28 & 0.78 \\
\hline Other years & 16.96 & & & \\
\hline ENSO: 1992 & 28.96 & 32 & 2.72 & 0.01 \\
\hline Other years & 16.09 & & & \\
\hline ENSO: 1997 & 22.03 & 32 & 1.04 & 0.30 \\
\hline Other years & 16.44 & & & \\
\hline
\end{tabular}

\section{Simultaneous sampling and evaluation of census techniques}

Of the 35 local species (Appendix 1), 30 were recorded at the baits for the 2-mo replicated-sites study. Their relative numbers showed a pronounced skew toward the less common species; eight species were seen or counted only one to three times. The remainder varied from abundant to scarce, but each was seen at least four times (Appendix 3).

The common species did not differ among sites, although 12 of 30 species were not recorded at all sites, and eight were rare. Trends across sites, for the entire assemblage, were closely similar. Between November and December, the increment in abundance was 2.6, 2.2, 3.5, and 2.5, respectively, and between December and January, it was $0,0,-0.2$, and 0 . The total counts ranked by site were relatively stable month-to-month, with sites 1 and 3 highest and similar ( 544 and 586 total bees), site 2 the poorest ( 387 bees) and site 4 intermediate ( 471 bees). Relative ranks were almost identical across census dates, differing only twice, with a change in rank order between sites 1 and 3 . Mean consistency for 24 species was $90 \%$. The most abundant bee at all sites was Euglossa imperialis. Only two of the 256 census count-days registered another species as more abundant. The top 10 species in abundance were similar across sites, with correspondence of 60-70\% each month (Appendix 2). Compared to the most abundant species (imperialis, dissimula, cingulata), all of the remaining top-10 species were similar, but differed in rank between sites.

If one tallied species not found in the top 10 at one site, but among the top 10 elsewhere, four or five additional species were in this category (Table 1). Peak abundance for a given species was similar across sites. Over one-half of the bees reached peak abundance with conspecifics in all four sites, simultaneously (Appendix 3). Of the remainder, three displayed relatively flat abundance across the three censuses, whereas most were at peak abundance in two or three sites on the same date.

Euglossa imperialis, the most abundant bee, arrived first in nearly all censuses. However, its arrival time was not correlated with its recorded abundance in the summed 98 censuses $(F=0.07, P=0.78)$. It arrived so quickly that no large spread occurred in arrival times, even over $20 \mathrm{yr}$. All four other individual species showed significant negative correlation between recorded abundance and time of first arrival (Euglossa bursigera, $F=12.25, P=0.0007 ;$ E. sapphirina, $F=7.01, P=0.009$; Eulaema cingulata, $F=10.47, P=0.001$; and $E$. meriana, $F=3.7, P=0.05$; df for all preceding statistics $=1,96)$. Mean elapsed time before first arrival was negatively correlated with the total number of bees recorded on a given day $(P<0.0001$, $\left.r^{2}=0.15\right)$. Thus, the general results show that more abundant bees arrived sooner at the baits. Individual species first arrived from two min to almost $4 \mathrm{~h}$ from the start of a census, with a mean of 78 min. Over the 20 -yr period scored for arrival times, there was no correlation between replicate and timing of first arrival $(P=0.09-0.86)$. However, Euglossa imperialis, one of the four species shown by regression analysis to decline, also showed a tendency toward later arrival at baits as the years progressed (correlation coefficient $-0.03, F=2.8, P=0.09$ ).

\section{DISCUSSION}

\section{Bee communities over time}

Insect sampling programs summarized by Southwood (1988) and others do not specifically treat bees, whereas studies conducted by Banazak (1995) and European workers (Matheson et al. 1996) discuss bee field censuses, but primarily for transect samples within agricultural areas. The potential for impact by invasive honey bees and the movement of hives in large numbers in and out of habitats are discussed elsewhere (Roubik 2000, Roubik and Wolda 2000). Work on euglossine bees in Amazonian and Atlantic forest in Brazil has been treated in preliminary detail by Powell and Powell (1987), Becker et al. (1991), Oliveira and Campos (1995), and Peruquetti et al. (1999). Some euglossine long-term data have been considered from a different standpoint, that of trends shared among species in three different forests (Roubik 1996a). My study in Parque Soberania clearly demonstrates that there was neither a decline in euglossine bees in over 20 years, nor did ENSO phenomena have an immediate negative impact. Rather, they appeared to increase bee abundance. No change in euglossine species composition occurred. Four species became statistically less abundant, whereas 32 species either increased or showed no change. Euglossine diversity may therefore be increasing in the habitat as a whole.

Plant-pollinator systems inherently possess wide variation (see Roubik 1996a,b). Surveys had limited application because 
dynamics in stable habitats were scarcely known, dynamics in unprotected habitats are expected to be less predictable, and all studies may be compromised by invasive species. As a preliminary study of bee abundance change in natural habitats, the results given here and in other studies show that populations change considerably between years, as revealed by a variety of census techniques. The census techniques were varied, but all attempted to embrace variation in space and time, at least on a local scale. Tropical and temperate sites and species appear to be similar over the short term, but there are as yet no comparable long-term data to evaluate. We can expect bee populations to double or halve from one year to the next. Some implications are summarized at the end of this paper.

The next step is to document a decline if it is occurring, and this requires a minimum of three years. To detect a steady trend with a probability of Type I error $<0.05$, four sequential surveys, with the resulting three intervals for assessment of trends, are necessary. Only then is there a probability of $0.037\left(1 / 3^{3}\right)$ of being misled to perceive that a significant trend exists when there is none. Continued sampling over the entire active period, and replicate samples within years or seasons, can establish whether field censuses are sensitive to regional trends, or can better show localized phenomena. Longer data series produce more meaningful abundance comparisons. For example, that neither of the two euglossine parasites (Exaerete frontalis and $E$. smaragdina) and none of the relatively rare, but evidently not transient, species declined during 21 years suggests that the habitat favors stability in this bee assemblage. More than twice as many species increased as declined. Conditions for euglossines may be improving.

\section{ENSO and the bees}

Weather was a factor that could explain abundance trends in bees studied in Panama. Pearson and Dressler (1985) also noted that interruption of the normal wet-season rains seemed to cause lower euglossine abundance in Amazonian Peru. Rainfall differed by $100 \%$ during the study period on Barro Colorado Island (see Roubik and Wolda 2000), but a previous analysis of euglossine bee abundance during the first seven years of the present data set (Roubik and Ackerman 1987) showed very high relative stability, compared to other insects, at three different forests. Multiple regression analysis using rain and honey bee abundance as independent variables showed that these were not determining recorded bee catches over 10-17 years of continuous data collection, considering both 15 native bee species and honey bees on BCI (Roubik and Wolda 2000).

The more extreme ENSO conditions during 1992 and 1997 could, in part, account for the recorded differences (Table 5 and Fig. 3). Interestingly, May of 1980 had the lowest figure among euglossine censuses taken in this month, but there was no correlation with annual rainfall (mean $2643 \mathrm{~mm}$, compared to 2776 for 1980). The rainy dry season in 1981 correlated with a slight decrease in bee abundance in May. Furthermore, splitting the census data into dry- and wet-season components (February and May) suggested a lag period of a few months before the extended dry-season flower abundance, or its absence, caused a change in absolute bee abundance. This was shown clearly by a substantial increase in May during 1992, whereas no such increase occurred in February. The ENSO produced a floral resource flush in the dry season, followed by an increase in bee populations (D. Roubik, S. J. Wright, and O. Calderon, unpublished data). The life cycle of euglossine bees involves a delay of about six weeks from egg to adult (Roubik 1989), which would produce the observed pattern. The year following a strong ENSO should register a significant decline in euglossine abundance, but this is the necessary consequence following a short-lived increase in resources and bee abundance.

\section{Euglossine sampling techniques and long-term sampling strategies}

A need for data applicable to conservation decisions has been mentioned in general works on insects (New 1998, Ghazoul and Hill 2000). Euglossine bees can be sampled in dense forests, and in a short time, using chemical baits that are intensely attractive to almost all local species. The correct strategy for sampling Euglossini, in order to detect changes in abundance, should employ both volatile and persistent chemical odor beacons (e.g., highly volatile cineole and much less volatile skatole or eugenol), and should assess the bees flying to them during a few hours, while volatile baits are replenished (see Roubik and Ackerman 1987). Fig. 5 illustrates the value of using baits for four hours. Temporal activity patterns perhaps differ among species, but rarer species appear to be slower to arrive, regardless of their size or flight range. Appendices 3 and 4 indicate that, although one good site may be adequate to attract most local species within one morning (see also the following discussion of simultaneous baiting results), a comparison of sites may show that some are considerably better than others.

Repeated or long-term trapping (e.g., Powell and Powell 1987, Becker et al. 1991, Roubik 1993, review in Peruquetti et al. 1999 ) is useful for work on local foraging behavior and bee diversity or on aspects of abundance. Keeping many traps in place for long periods of time seems too destructive, as thousands of bees in small areas were removed with only two McPhail traps (Powell and Powell 1987, Roubik 1993). Removing rare species or others using occasional destructive sampling may not harm the population, although rare species are expected to be more vulnerable to destructive sampling. Taxonomically difficult species need to be collected and kept as vouchers. However, the roughly 50,000 bees counted and identified at Pipeline Road would, as voucher specimens, perhaps lead to questions about a human intervention having produced any documented decline. The mimicry mentioned in Methods certainly led to faulty identification of medium-sized, predominantly green species: tridentata, deceptrix, despecta, variabilis, hemichlora, townsendi, and cyanaspis. Even under microscopic examination, bees collected in a liquid medium are not easy to identify, and mistakes are certain (Becker et al. 1991). I minimized this problem by making many counts.

In South America, capturing euglossine males at baits seems to be a necessary part of studies because Euglossa ignita chases others from baits and interrupts the baiting process (personal observation). Such chaos lessens the effectiveness or replicability of euglossine studies. Fortunately, bees in Panama showed few such interactions. Most were observed or collected by hand and were identified with a hand lens when they landed on bait pads (Fig. 4), although most were "timid" until brushing baits with the forelegs. Traps seem to be a viable alternative or supplement to studies on eulgossine assemblages. Yet, their potential for negative long-term effects on these bees and the flowers that they service should be taken seriously.

Analyses presented here repeated the work of Armbruster (1993) on spatial consistency, extending it to patterns in time. Although absolute numbers scored at particular baiting stations are bound to vary, they generally followed the same seasonal trends, had closely similar peaks for individual species, shared most of the "top-10" species, or contained the same most abundant species. The rank abundance of less common species varied widely (Appendix 3). Each site presented a different characteristic bee abundance, and some had notably fewer individuals than others. No conclusions regarding species number or 
absolute rank among species within the habitat seem feasible from such surveys, although the trends and extensive census data seemed reliable for studies of diversity and population fluctuation. Similar observations have been made concerning results of bee censuses at flower patches (Ginsberg 1983) or euglossine bee arrival at chemical baits in different strata within the forest (Roubik 1993, Oliveira and Campos 1996). All of these studies show that timing and spatial relationships are, not surprisingly, important in the distribution patterns and abundance of bees. The significance of Ginsberg's work, however, was that more attractive resources could appear at any time, making a particular floral census site less attractive and, therefore, less able to show change in bee abundance within the habitat. Furthermore, Ginsberg's study primarily involved honey bees, which often recruit in "all or none" fashion. Chemical baiting techniques used here were sensitive to bee abundance because the first species to arrive at the chemical baits were very likely to be recorded most often. Extension of baiting through time on a given day produced more species (Fig. 5). Extension of baiting through space would presumably make the same improvement, considering species richness or rank abundance. Replication in time can arguably be substituted for replication in space (e.g., Wolda 1992), particularly for bees that fly large distances through the day. Consistency in peak abundance was not variable as a function of either raw abundance at a site or among aggregate sites. Thus, raw trends, but certainly not their magnitude, were adequately revealed through even short application of the chemical baiting technique.

Although first arrival was apparently determined by absolute abundance in the habitat, alternative hypotheses have not been exhausted. Because males compete intensely for natural chemicals that are rare in the forest (Eltz et al. 1999), it is unlikely that substantial differences in olfactory ability exist among species. More pronounced incongruity in bee counts might arise from species' tendencies to remain longer on the baits, or to make return trips during the four-hour census, or to come to baits from greater distances. The anomalous, extremely high number of Euglossa dissimula observed in May 2000 was probably due to proximity of the baiting site to a male aggregation such as that witnessed by Peruquetti (2000) for another Euglossa species in natural forest. Removal of the most common bees at baits during unusually high abundance did not reduce their number in counts shortly afterwards (personal observations). Turnover on baits for these bees thus seemed high. Nonetheless, species differences in performance and persistence at baits undoubtedly exist. The general caution should remain that abundance figures are not necessarily relative between species, but can be used to test for changes over time. In conclusion, to surmise from a baseline now established on bee abundance in nature preserves, any report finding that absolute abundance declined to $25 \%$ of the level recorded two years before contains no real information on trends. Increasing the length of the study and the number of observations, only by a moderate amount, would provide a much better appreciation of population change.

\section{RESPONSES TO THIS ARTICLE}

Responses to this article are invited. If accepted for publication, your response will be hyperlinked to the article. To submit a comment, follow this link. To read comments already accepted, follow this link.

\section{Acknowledgments:}

I thank J. Ackerman for starting this study, and C. Dodson, N. Williams, L. S. Kimsey, R. L. Dressler, and J. Moure for making it possible. Thanks are also due to the two reviewers, C. S. Holling, and to participants of the NCEAS workshop on pollinator decline in the United States.

\section{LITERATURE CITED}

Ackerman, J. D. 1983. Diversity and seasonality of male euglossine bees (Hymenptera: Apidae) in central Panama. Ecology 64:274-283.

Armbruster, W. S. 1993. Within-habitat heterogeneity in baiting samples of male euglossine bees: possible causes and implications. Biotropica 25:122-128.

Banazak, J., editor. 1995. Changes in fauna of wild bees in Europe. Pedagogical University, Bydgszcz, Poland.

Basset, Y., V. Novotny, S. E. Miller, and N. D. Springate. 1998. Assessing the impact of forest disturbance on tropical invertebrates: some comments. Journal of Applied Ecology 35:461-466.

Becker, P., J. S. Moure, and F. J. Peralta. 1991. More about euglossine bees in Amazonian forest fragments. Biotropica 23:586-591.

Buchmann, S. L., and G. P. Nabhan. 1996. The forgotten pollinators. Island Press, Washington, D.C., USA.

Cane, J. H., and J. A. Payne. 1993. Regional, annual, and seasonal variation in pollinator guilds: intrinsic traits of bees (Hymenoptera: Apoidea) underlie their patterns of abundance at Vaccinium ashei (Ericaceae). Annals of the Entomological Society of America 88:577-588.

Dressler, R. L. 1982. Biology of the orchid bees (Euglossini). Annual Review of Ecology and Systematics 13:373-394.

Eltz, T., W. M. Whitten, D. W. Roubik, and K. E. Linsenmair. 1999. Fragrance collection, storage, and accumulation by individual male orchid bees. Journal of Chemical Ecology 25:157-176.

Frankie, G. W., R. W. Thorp, L. E. Newstrom-Lloyd, M. A. Rizzardi, J. F. Barthell, T. L. Griswold, J.-Y. Kim, and S. Kappagoda. 1998. Monitoring solitary bees in modified wildland habitats: implications for bee ecology and conservation. Enviromental Entomology 27:1137-1148.

Ghazoul, J., and J. Hill. 2000. Impacts of selective logging on tropical forest invertebrates In R. A. Fimbel, A. Grajal, and J. G. Robinson, editors. Conserving wildlife in managed tropical forests. Columbia University Press, New York, New York, USA, in 
press.

Ginsberg, H. S. 1983. Foraging ecology of bees in an old field. Ecology 64:165-175.

Hilborn, R., and M. Mangel. 1997. The ecological detective. Princeton Monographs in Population Biology. Princeton University Press, Princeton, New Jersey, USA.

Janzen, D. H., P. J. DeVries, M. L. Higgins, and L. S. Kimsey. 1982. Seasonal and site variation in Costa Rican euglossine bees at chemical baits in lowland deciduous and evegreen forests. Ecology 63:66-74.

Matheson, A., S. L. Buchmann, C. O'Toole, P. Westrich, and I. H. Williams, editors. 1996. The conservation of bees. Academic Press, London, UK.

New, T. R. 1998. Invertebrate surveys for conservation. Oxford University Press, New York, New York, USA.

Niemi, G., J. Hanowski, P. Helle, R. Howe, M. Monkkonen, L. Venier, and D. Welsh. 1998. Ecological sustainability of birds in boreal forests. Conservation Ecology 2:(2):17. [online] URL: http://www.consecol.org/vol2/iss2/art17

Oliveira, M. L., and L. A. O. Campos. 1995. Abundancia, riqueza e diversidade de abelhas Euglossinae (Hymenoptera, Apidae) em florestas continuas de terra firme na Amazonia Central, Brasil. Revista Brasileira de Zoologia 12::547-556.

Oliveira, M. L., and L. A. O. Campos. 1996. Preferencia por estratos florestais e por substancias odoriferas em abelhas Euglossinae (Hymenoptera, Apidae). Revista Brasileira de Zoologia 13:1075-1085.

Pearson, D. L., and R. L. Dressler. 1985. Two-year study of male orchid bee (Hymenoptera: Apidae: Euglossini) attraction to chemical baits in lowland south-eastern Peru. Journal of Tropical Ecology 1:37-54.

Peruquetti, R. C. 2000. Function of fragrances collected by euglossine males (Hymenoptera: Apidae). Entomologica Generalis 25: 33-37.

Peruquetti, R. C., L. A. O. Campos, C. D. P. Coelho, C. V. M. Abrantes, and L. C. O. Lisboa. 1999. Abelhas Euglossini (Apidae) de àreas de Mata Atlântica: abundância, riqueza e aspectos biològios. Revista Brasileira de Zoologia 16:101-118.

Powell, A. H., and G. V. N. Powell. 1987. Population dynamics of male euglossine bees in amazonian forest fragments. Biotropica19:176-179.

Roubik, D. W. 1983. Experimental community studies: time-series tests of competition between African and neotropical bees. Ecology 64:971-978.

Roubik, D. W. 1989. Ecology and natural history of tropical bees. Cambridge University Press, Cambridge, Massachusetts, USA.

Roubik, D. W. 1992. Loose niches in tropical communities: why are there so many trees and so few bees? Pages $327-354$ in M. D. Hunter, T. Ohgushi, and P. W. Price, editors. Effects of resource distribution on animal-plant interactions. Academic Press, San Diego, California, USA.

Roubik, D. W. 1993. Tropical pollinators in the canopy and understory: field data and theory for stratum "preferences." Journal of Insect Behavior 6:659-673.

Roubik, D. W. 1996a. Measuring the meaning of honey bees. Pages 163-172 in A. Matheson, S. L. Buchmann, C. O'Toole, P. Westrich, and I. H. Williams, editors. The conservation of bees. Academic Press, London, UK.

Roubik, D. W. 1996b. African honey bees as exotic pollinators in French Guiana. Pages 173-182 in A. Matheson, S. L. Buchmann, C. O'Toole, P. Westrich, and I. H. Williams, editors. The conservation of bees. Academic Press, London, UK.

Roubik, D. W. 2000. Pollination system stability in tropical America. Conservation Biology 14:1235-1236.

Roubik, D. W., and J. D. Ackerman. 1987. Long-term ecology of euglossine orchid-bees (Apidae: Euglossini) in Panama. Oecologia 73:321-333.

Roubik, D. W., and H. Wolda. 2000. Do honey bees matter? Dynamics and abundance of native bees before and after honey bee invasion. Population Ecology, in press.

Southwood, T. R. E. 1988. Ecological methods. Third edition. Methuen, London, UK.

SPSS. 1997. SYSTAT 7.0 for Windows. SPSS Inc.

Wolda, H. 1979. Fluctuations in abundance of tropical insects. American Naturalist 112:1017-1045.

Wolda, H. 1992. Trends in abundance of tropical forest insects. Oecologia 89:47-52.

Wolda, H., and D. W. Roubik. 1986. Nocturnal bee abundance and seasonal bee activity in a Panamanian forest. Ecology 67:426-433.

Wright, S. J., C. Carrasco, O. Calderon, and S. Paton. 1999. The El Niño southern oscillation, variable fruit production, and famine in a tropical forest. Ecology 80:1632-1647. 
Total counts of all euglossine bee species recorded at the principal Pipeline Road site, Parque Soberania, Panama (1979-2000).

\begin{tabular}{|c|c|c|c|c|c|}
\hline $\begin{array}{l}\text { No. } \\
\text { bees }\end{array}$ & Bee species & No. bees & Bee species & No. bees & Bee species \\
\hline 556 & Eug. allosticta & 4835 & Eug. dissimula & 1244 & Eul. meriana \\
\hline 25 & Euf. anisochlora & 275 & Eug. dodsoni & 1109 & Eug. mixta \\
\hline 4 & Eug. asarophora & 1679 & Eug. dressleri & 2369 & Eul. nigrita \\
\hline 290 & Eug. azureoviridis & 1 & Euf. duckei & 114 & Euf. ornata \\
\hline 356 & Eul. bombiformis & $\overline{1}$ & Euf. dress/eri & 266 & Euf. pulchra \\
\hline 1266 & Eug. bursigera & 9 & Eug. flammea & 4 & Eug. purpurea \\
\hline 317 & Eug. championi & 464 & Exa. frontalis & 886 & Eug. sapphirina \\
\hline 3220 & Eul. cingulata & 187 & $\begin{array}{l}\text { Eug. } \\
\text { gorgonensis }\end{array}$ & 95 & Euf. schmidtiana \\
\hline 1244 & Eug. cognata & 233 & Eug. hansoni & 30 & Exa. smaragdina \\
\hline 18 & Euf. concava & 9 & Eug. hemichlora & 2 & Eul. speciosa \\
\hline 544 & Eug. crassipunctata & 131 & $\begin{array}{l}\text { Eug. } \\
\text { heterosticta }\end{array}$ & 4283 & Eug. tridentata \\
\hline 45 & Eug. cyanaspis & 4 & Eug. ignita & 345 & Eug. variabilis \\
\hline 36 & Eug. cybelia & 78 & Eug. igniventris & 21 & Eug. villosiventris \\
\hline 66 & Eug. deceptrix & 15688 & Eug. imperialis & & \\
\hline 4570 & Eug. despecta & 2 & Euf. Iucifera & & \\
\hline
\end{tabular}

Note: Genera are abbreviated as Eug., Euglossa; Euf., Eufriesea; and Eul., Eulaema.

\section{APPENDIX 2}

May bee counts at the principal Pipeline Road site, Parque Soberania, Panama, during 1980-2000.

\begin{tabular}{|c|c|c|c|c|c|c|c|c|c|c|c|c|c|c|c|c|c|c|}
\hline Species & 2000 & 1999 & 1998 & 1997 & 1996 & 1992 & 1991 & 1990 & 1989 & 1988 & $\mid 1987$ & 1986 & 1985 & 1984 & 1983 & 1982 & 1981 & 1980 \\
\hline Eug. allosticta & 6 & 12 & 3 & 1 & 7 & 6 & 7 & 4 & 3 & 2 & 8 & 4 & 0 & 10 & 1 & 8 & 0 & 4 \\
\hline \begin{tabular}{|l} 
Euf. \\
anisochlora
\end{tabular} & 0 & 0 & 0 & 0 & 0 & 0 & 1 & 1 & 1 & 0 & 0 & 2 & 0 & 0 & 1 & 4 & 4 & 1 \\
\hline \begin{tabular}{|l} 
Eug. \\
azureoviridis
\end{tabular} & 0 & 6 & 8 & 2 & 1 & 3 & 7 & 3 & 3 & 2 & 3 & 3 & 4 & 1 & 5 & 8 & 3 & 1 \\
\hline \begin{tabular}{|l} 
Eul. \\
bombiformis
\end{tabular} & 15 & 2 & 2 & 2 & 1 & 3 & $\overline{1}$ & 6 & 4 & 2 & 0 & 9 & $\overline{1}$ & 3 & $\overline{4}$ & $\overline{1}$ & 0 & 0 \\
\hline \begin{tabular}{|l|} 
Eug. \\
bursigera
\end{tabular} & 37 & 40 & 36 & 15 & 9 & 21 & 17 & 22 & 16 & 10 & 7 & 31 & 13 & 11 & 21 & 4 & 8 & 9 \\
\hline \begin{tabular}{|l} 
Eug. \\
championi
\end{tabular} & 6 & $\overline{9}$ & 2 & 0 & 0 & 0 & $\overline{1}$ & 4 & 4 & 3 & 1 & 4 & 2 & $\overline{4}$ & $\overline{4}$ & $\overline{1}$ & 4 & 0 \\
\hline Eul. cingulata & 26 & 6 & 9 & 10 & 34 & 44 & 14 & 38 & 36 & 34 & 11 & 23 & 36 & 2 & 56 & 40 & 21 & 23 \\
\hline Eug. cognata & 24 & 61 & 64 & 13 & 14 & 17 & 5 & 20 & 16 & 11 & $\overline{11}$ & 6 & 8 & 38 & 8 & 17 & 7 & 0 \\
\hline \begin{tabular}{|l} 
Eug. \\
crassipunctata
\end{tabular} & 23 & 21 & 14 & 8 & 13 & 17 & 1 & 14 & 13 & 12 & 5 & 4 & 4 & 5 & 4 & 12 & 8 & 0 \\
\hline $\begin{array}{l}\text { Eug. } \\
\text { cyanaspis }\end{array}$ & 0 & 2 & 0 & 4 & 4 & 0 & 3 & 0 & 0 & 0 & $\overline{0}$ & 0 & 0 & 0 & 0 & 0 & 0 & 4 \\
\hline Eug. cybelia & 2 & 2 & 0 & 1 & 0 & 0 & 0 & 0 & 0 & 0 & 1 & 0 & 2 & 1 & 0 & 0 & 0 & 0 \\
\hline $\begin{array}{l}\text { Eug. } \\
\text { deceptrix }\end{array}$ & 0 & 2 & 0 & 0 & 0 & 0 & 0 & 15 & 8 & 1 & 0 & 0 & 2 & 0 & 0 & 0 & 0 & 0 \\
\hline Eug. despecta & $\mid 111$ & 74 & 112 & 131 & 63 & 150 & 89 & 37 & 77 & 117 & 64 & 48 & 50 & 86 & 113 & 57 & 88 & 29 \\
\hline $\begin{array}{l}\text { Eug. } \\
\text { dissimula }\end{array}$ & 332 & 43 & 26 & 250 & 246 & 202 & 88 & 65 & 159 & 253 & 40 & 60 & 46 & 28 & 9 & 56 & 31 & 7 \\
\hline Eug. dodsoni & 0 & 0 & 2 & 0 & 0 & $\overline{1}$ & 0 & 3 & 2 & 0 & 0 & 2 & 6 & 2 & 5 & 2 & 5 & 5 \\
\hline Eug. dressleri & 2 & 6 & 1 & 4 & 6 & 3 & 1 & 3 & 4 & 5 & 3 & 5 & 6 & 9 & 11 & 7 & 2 & 3 \\
\hline Eug. flammea & 0 & 0 & $\overline{1}$ & 0 & $\overline{0}$ & 0 & 0 & 0 & 0 & 0 & 0 & $\overline{0}$ & 0 & 0 & 0 & 0 & 0 & 0 \\
\hline Exa. frontalis & $\overline{11}$ & $\overline{4}$ & $\overline{9}$ & $\overline{12}$ & 3 & $\overline{11}$ & $\overline{8}$ & $\overline{11}$ & $\overline{9}$ & $\overline{6}$ & 3 & $\overline{6}$ & $\overline{11}$ & $\overline{6}$ & $\overline{12}$ & $\overline{4}$ & $\overline{11}$ & 4 \\
\hline
\end{tabular}




\begin{tabular}{|c|c|c|c|c|c|c|c|c|c|c|c|c|c|c|c|c|c|c|}
\hline $\begin{array}{l}\text { Eug. } \\
\text { gorgonensis }\end{array}$ & 3 & 2 & 2 & 2 & 1 & 2 & 0 & 0 & 2 & 3 & 0 & 1 & 2 & 2 & 2 & 0 & 8 & 3 \\
\hline Eug. hansoni & 3 & 0 & 1 & 3 & 2 & 4 & 15 & 2 & 6 & 9 & 0 & 2 & 6 & 0 & 10 & 4 & 1 & 2 \\
\hline $\begin{array}{l}\text { Eug. } \\
\text { hemichlora }\end{array}$ & 0 & 0 & 1 & 0 & 0 & 0 & 0 & 0 & 0 & 0 & 0 & 0 & 0 & 0 & 0 & 0 & 0 & 0 \\
\hline $\begin{array}{l}\text { Eug. } \\
\text { heterosticta }\end{array}$ & 0 & 0 & 1 & 0 & 0 & 2 & 3 & 0 & 0 & 0 & 0 & 4 & 0 & 1 & 1 & 5 & 0 & 3 \\
\hline $\begin{array}{l}\text { Eug. } \\
\text { igniventris }\end{array}$ & 1 & 0 & 0 & 1 & 0 & 0 & 0 & 0 & 0 & 0 & 0 & 0 & 0 & 2 & 0 & 0 & 1 & 0 \\
\hline $\begin{array}{l}\text { Eug. } \\
\text { imperialis }\end{array}$ & 145 & 187 & 82 & 160 & 160 & 231 & 146 & 100 & 116 & 132 & 130 & 95 & 139 & 175 & 208 & 162 & 151 & 123 \\
\hline Eul. meriana & 25 & 32 & 49 & 7 & 7 & 23 & 18 & 5 & 7 & 8 & 13 & 8 & 9 & 16 & 6 & 20 & 7 & 4 \\
\hline Eug. mixta & 15 & 54 & 14 & 11 & 7 & 34 & 24 & 12 & 11 & 9 & 4 & 8 & 9 & 26 & 9 & 25 & 8 & 10 \\
\hline Eul. nigrita & 15 & 43 & 6 & 5 & 19 & 39 & 16 & 36 & 24 & 12 & 10 & 9 & 16 & 39 & 28 & 66 & 32 & 16 \\
\hline Euf. ornata & 0 & 0 & 0 & 0 & 0 & 0 & 0 & 0 & 1 & 1 & 1 & 1 & 0 & 0 & 0 & 0 & 0 & 0 \\
\hline Euf. pulchra & 3 & 3 & 3 & 0 & 1 & 0 & 1 & 1 & 2 & 2 & 0 & 1 & 3 & 4 & 0 & 8 & 1 & 3 \\
\hline $\begin{array}{l}\text { Eug. } \\
\text { sapphirina }\end{array}$ & 8 & 14 & 18 & 18 & 4 & 27 & 14 & 4 & 11 & 17 & 3 & 8 & 6 & 9 & 14 & 28 & 5 & 3 \\
\hline \begin{tabular}{|l} 
Euf. \\
schmidtiana
\end{tabular} & $\overline{2}$ & $\overline{1}$ & 3 & 0 & $\overline{0}$ & $\overline{0}$ & 0 & $\overline{1}$ & 2 & 3 & 1 & 10 & 0 & 0 & 0 & 0 & 0 & 1 \\
\hline $\begin{array}{l}\text { Exa. } \\
\text { smaragdina }\end{array}$ & 0 & 1 & 0 & 1 & 1 & 0 & 0 & 0 & 1 & 1 & 0 & 0 & 0 & 0 & 1 & 0 & 0 & 1 \\
\hline $\begin{array}{l}\text { Eug. } \\
\text { tridentata }\end{array}$ & 39 & 75 & 37 & 59 & 85 & 77 & 53 & 14 & 25 & 36 & 19 & 17 & 48 & 70 & 45 & 58 & 26 & 38 \\
\hline Eug. variabilis & 1 & 5 & 1 & 4 & 2 & 6 & 0 & 3 & 4 & 5 & 0 & 3 & 3 & 0 & 0 & 0 & 3 & 5 \\
\hline $\begin{array}{l}\text { Eug. } \\
\text { villosiventris }\end{array}$ & 0 & 0 & 0 & 0 & 0 & 0 & 0 & 0 & 0 & 0 & 0 & 0 & 1 & 0 & 0 & 0 & 0 & 0 \\
\hline Totals & 855 & 707 & 507 & 724 & 690 & 923 & 533 & 424 & 560 & 696 & 338 & 374 & 433 & 550 & 578 & 597 & 435 & 302 \\
\hline
\end{tabular}

Note: Genera are abbreviated as Eug., Euglossa; Euf., Eufriesea; and Eul., Eulaema.

\section{APPENDIX 3}

Bee abundances scored on simultaneous census replicates, November and December 1997 and January 1998 (see Methods).

\begin{tabular}{|c|c|c|c|c|c|c|c|c|c|c|c|c|c|}
\hline & \multicolumn{13}{|c|}{ Raw abundance (pooled across baits) } \\
\hline Bee species & Date & 1 & 2 & 3 & 1 & 2 & 3 & 1 & 2 & 3 & 1 & 2 & 3 \\
\hline & Site & 1 & 1 & 1 & 2 & 2 & 2 & 3 & 3 & 3 & 4 & 4 & 4 \\
\hline Eug. allosticta & & & 2 & 2 & & 2 & 1 & & 5 & 1 & & & \\
\hline $\begin{array}{l}\text { Eug. } \\
\text { azureoviridis }\end{array}$ & & & 1 & & & & & & & & & 2 & \\
\hline \begin{tabular}{|l} 
Eul. \\
bombiformis
\end{tabular} & & 2 & 4 & 2 & & 5 & 6 & 1 & 14 & 3 & 1 & 3 & \\
\hline \begin{tabular}{|l|} 
Eug. \\
bursigera
\end{tabular} & & 7 & 10 & 13 & 5 & 2 & 9 & 5 & 5 & 12 & 7 & 3 & 3 \\
\hline \begin{tabular}{|l} 
Eug. \\
championi
\end{tabular} & & 2 & 1 & & 1 & & & & 1 & 1 & 1 & 1 & 1 \\
\hline Eul. cingulata & & & 22 & 12 & 7 & 16 & 19 & & 22 & 27 & 10 & 9 & 22 \\
\hline Eug. cognata & & & 11 & 6 & & 2 & 4 & 2 & 3 & 2 & 1 & 4 & 4 \\
\hline Euf. concava & & & & 1 & & & 1 & & 1 & 1 & 1 & & \\
\hline \begin{tabular}{|l|} 
Eug. \\
crassipunctata
\end{tabular} & & 2 & 7 & 10 & & & 4 & 2 & 1 & 9 & 3 & 2 & 8 \\
\hline \begin{tabular}{|l|} 
Eug. \\
cyanaspis
\end{tabular} & & & 1 & & & & & & & & & & \\
\hline Eug. despecta & & 2 & 4 & 30 & 1 & 5 & 23 & & 6 & 10 & 2 & 5 & 26 \\
\hline \begin{tabular}{|l|} 
Eug. \\
dissimula
\end{tabular} & & 1 & 24 & 43 & 6 & 10 & 15 & 9 & 25 & 52 & 8 & 4 & 51 \\
\hline Eug. dodsoni & & 1 & 1 & & & & & & & & 1 & & \\
\hline Eug. dressleri & & 3 & 3 & 3 & 3 & 1 & 4 & 3 & 8 & 4 & & 14 & 8 \\
\hline
\end{tabular}




\begin{tabular}{|c|c|c|c|c|c|c|c|c|c|c|c|c|}
\hline Exa. frontalis & 1 & 2 & 1 & 1 & 2 & & 3 & 2 & & & 3 & \\
\hline $\begin{array}{l}\text { Eug. } \\
\text { gorgonensis }\end{array}$ & 1 & & & & & & 1 & & & 1 & 2 & \\
\hline Eug. hansoni & & & & & & & & & 1 & 1 & & \\
\hline \begin{tabular}{|l|} 
Eug. \\
hemichlora
\end{tabular} & & 2 & & & 3 & & & 1 & & & & \\
\hline \begin{tabular}{|l|} 
Eug. \\
heterosticta
\end{tabular} & & & 2 & & & 2 & & & & & & \\
\hline \begin{tabular}{|l} 
Eug. \\
imperialis
\end{tabular} & 52 & 92 & 49 & 34 & 75 & 32 & 40 & 141 & 50 & 29 & 118 & 47 \\
\hline Eul. meriana & 2 & 9 & 9 & 2 & 6 & 4 & 6 & 3 & 6 & 6 & 3 & 3 \\
\hline Eug. mixta & & 4 & 11 & & 1 & 4 & & 4 & 6 & & & 2 \\
\hline Eul. nigrita & 4 & 6 & 6 & 5 & 14 & 15 & 1 & 6 & 10 & 2 & 5 & 8 \\
\hline Euf. ornata & & & & & & & & & & & & 1 \\
\hline Euf. pulchra & 1 & 2 & 5 & 2 & 4 & 3 & 2 & 16 & 7 & 2 & 7 & 2 \\
\hline Eug. purpurea & & & & & 1 & & & & & & & \\
\hline $\begin{array}{l}\text { Eug. } \\
\text { sapphirina }\end{array}$ & 3 & 5 & 5 & 1 & 1 & 3 & 2 & 3 & 2 & 1 & 3 & 5 \\
\hline \begin{tabular}{|l|} 
Eug. \\
tridentata
\end{tabular} & 3 & 8 & 21 & 2 & 6 & 11 & 2 & 10 & 25 & & 4 & 9 \\
\hline $\begin{array}{l}\text { Eug. } \\
\text { turbinifex }\end{array}$ & & & & & & & & & & & 2 & \\
\hline Eug. variabilis & & 5 & & & 1 & & & & 1 & & & \\
\hline
\end{tabular}

Note: Genera are abbreviated as Eug., Euglossa; Euf., Eufriesea; and Eul., Eulaema.

\section{APPENDIX 4}

Euglossine bees from the simultaneous census study of 1997-1998 (see Appendix 3) ranked "top 10" in abundance, in descending order: (a) within a single site (site 1, the long-term census site of Roubik and Ackerman 1987) on different census months, and (b) within the four combined sites on single census months.

\begin{tabular}{|c|c|c|c|}
\hline & \multicolumn{3}{|c|}{ Sample month } \\
\hline Rank & November & December & January \\
\hline \multicolumn{4}{|c|}{ a) Rank within a single site (site 1 ) } \\
\hline 10 & Eug. imperialis & Eug. imperialis & Eug. imperialis \\
\hline 9 & Eug. bursigera & Eug. dissimula & Eug. dissimula \\
\hline 8 & Eul.nigrita & Eul. cingulata & Eug. despecta \\
\hline 7 & Eug. tridentata & Eug. cognata & Eug. tridentata \\
\hline 6 & Eug. dressleri & Eug. bursigera & Eug. bursigera \\
\hline 5 & Eug. sapphirina & Eul. meriana & Eul. cingulata \\
\hline 4 & Eug. championi & Eug. tridentata & Eug. mixta \\
\hline 3 & Eug. despecta & Eug. crassipunctata & Eug. crassipunctata \\
\hline 2 & Eug. crassipunctata & Eul. nigrita & Eul. meriana \\
\hline 1 & Eul. meriana & Eug. variabilis & Eug. cognata \\
\hline
\end{tabular}

b) Rank within four combined sites

\begin{tabular}{|c|c|c|c|}
\hline 10 & Eug. imperialis & Eug. imperialis & Eug. imperialis \\
\hline \hline 9 & Eug. bursigera & Eug. dissimula & Eug. dissimula \\
\hline 8 & Eul. nigrita & Eul. cingulata & Eug. despecta \\
\hline 7 & Eug. tridentata & Eug. cognata & Eug. tridentata \\
\hline 6 & Eug. dressleri & Eug. bursigera & Eug. bursigera \\
\hline 5 & Eug. sapphirina & Eul. meriana & Eul. cingulata \\
\hline 4 & Eug. championi & Eug. tridentata & Eug. mixta \\
\hline 3 & Eug. despecta & Eug. crassipunctata & Eug. crassipunctata \\
\hline 2 & Eug. crassipunctata & Eul. nigrita & Eul. meriana \\
\hline 1 & Eul. meriana & Eug. variabilis & Eug. cognata \\
\hline \hline & Eug. dissimula* & Eul. bombiformis* & Eul. bombiformis* \\
\hline \hline & Euf. pulchra* & Euf. pulchra* & Eul. nigrita* \\
\hline
\end{tabular}




\begin{tabular}{|l|l|c|c|}
\hline \multicolumn{1}{|l|}{} & Exa. frontalis* & Eug. hemichlora* & Eug. dressleri* \\
\hline & Eug. cognata* & Eug. dressleri* & Eug. crassipunctata* \\
\hline & Eug. despecta* & Eug. sapphirina* & \\
\hline
\end{tabular}

*Species that are within the top 10 at some sites.

Note: Genera are abbreviated as Eug., Euglossa; Euf., Eufriesea; and Eul., Eulaema.

\section{Address of Correspondent:}

David Ward Roubik

Smithsonian Tropical Research Institute

Apartado 2072 Balboa, Panama, and

Smithsonian Institution

Washington, D.C. 20560-0580 USA

Phone: 011-507-227-6022

roubikd@tivoli.si.edu

Home | Archives | About | Login | Submissions | Notify | Contact | Search 